\title{
ESTUDIO POLINICO DE SEIS YACIMIENTOS DEL SURESTE ESPAÑOL
}

\author{
POR
}

\author{
PILAR LOPEZ (*)
}

RESUMEN Se presenta el estudio de seis análisis polínicos efectuados en yacimientos arqueológicos de las provincias de Almería y Murcia, abarcando un período comprendido entre el final del Pleistoceno y el Holoceno. Culturalmente se enmarcan entre el Solutrense (Cueva Ambrosio) y la Edad del Bronce (nivel III de la Cueva del Calor), si bien la mayoría corresponde al Calcolítico del Sureste. El paisaje en todo este tiempo no ha variado mucho, si bien puede observarse en el momento actual un aumento de la desertización, favorecida en gran parte por la acción del hombre sobre su medio. Las especies consideradas como "tipicamente mediterráneas" están presentes desde el Pleistoceno.

ABSTRACT We present a palynological study of six late Pleistocene and Holocene archaeological sites from the provinces of Almeria and Murcia. They span cultural periods from the Solutrean (Cueva de Ambrosio) to the Bronze Age (level III of Cueva del Calor), although most of them belong to the Chalcolithic period. Throughout this period, the vegetation was similar to that of the present day, although there has been a recent increase in aridity, largely as a result of human interference with the environment. Mediterranean species have been present since the Pleistocene.

Palabras clave: Palinología arqueológica. Almería. Murcia.

\section{INTRODUCCION}

Presentamos con este trabajo el resultado de seis análisis polínicos realizados sobre sedimentos arqueológicos correspondientes a diversas etapas culturales. Cuatro de éstos se enmarcan dentro de un Proyecto de investigación que se viene realizando desde el año 85 sobre los aspectos socioeconómicos del inicio de la metalurgia en esta zona.

Entendemos por Sureste las actuales provincias de Murcia y Almería, con caracteres climáticos y geográficos muy similares. Los análisis efectuados se sitúan en ambas provincias, enmarcándose cinco de ellos en el Calcolítico-Bronce, y uno en el Solutrense.

(*) Departamento de Prehistoria del C.E.H. 
Consideramos que la mejor forma de aproximarnos a su estudio es seguir un orden cronológico, por este motivo empezaremos por el correspondientes al Solutrense.

\section{Cueva de Ambrosio}

Se sitúa en una zona montañosa al Norte de la provincia de Almería, próxima a los llanos que unen Caravaca de la Cruz con la Puebla de Don Fadrique. El yacimiento se abre en un cantil de 100 metros de altura, formado por calizas del Burdigaliense superior-Langhiense inferior, muy ricas en biomicritas de algas con fósiles (Ripoll López, 1986).

\section{Vegetación actual:}

Se trata de la típica vegetación mediterránea de árboles esclerófilos de tipo mediterráneo, propia de suelos calizos: Chamaerops humilis, Pinus halepensis, Quercus ruber, Mirtus communis y Pistacia lentiscus. En la zona de Vélez, la vegetación se compone de extensos pinares y encinares. Como sotobosque están presentes Juniperus thurifera, Lavandula officinalis, Lonicera periclymeum, Juniperus communis, Pistacia lentiscus, Rosmarinus officinalis, etc.

\section{Estratigrafia arqueológica:}

Presenta un total de siete niveles, localizados durante el sondeo efectuado en 1983.

Nivel VII: Arcilla de descalcificación compacta, en forma de cono, buzando hacia el SW. Arqueológicamente estéril, sin evidencia de ocupación humana.

Nivel VI: Matriz arcillosa, menos compacta que el anterior. Nivel con hogares. Aparecen gran cantidad de restos, tanto líticos como de fauna.

Nivel V: Se corresponde con la parte superior del VII. Arcilla suelta, sin industria lítica, pero con restos de fauna.

Nivel IV: Nivel con hogares. Matriz arcillosa con abundante industria lítica.

Nivel III: Matriz de arcilla suelta, estéril arqueológicamente, pero con abundante fauna, principalmente lagomorfos y microfauna.

Nivel II: Ultimo de ocupación humana. Arcilla suelta con abundante industria lítica: raspadores, puntas de muesca y hojitas de dorso, así como algunos ejemplos de industria ósea.

Nivel I: Arqueológicamente estéril. Matriz arcillosa con fauna de lagomorfos.

Todos los datos expuestos hasta ahora, tanto los de geomorfología como los de vegetación y arqueológicos, proceden de la Tesis doctoral de S. Ripoll (1987) a quien agradecemos su ayuda.

\section{Muestreo y tratamiento de las muestras:}

Al finalizar la campaña de 1986 tomamos un total de 65 muestras, cada $5 \mathrm{~cm}$., sobre un corte de 6 metros. Se escogió el corte Este por incluir todos los niveles excavados. Este se dividió a su vez en dos zonas, pues el nivel VI se acuñaba en el límite de dos cuadrículas y no podia muestrearse en una sola columna. La denominada Sur comprende los niveles VIIb, VIIa, VI y V, siendo el VI atribuible al Solutrense medio. La columna Norte incluye los VIIb, VIIa, V, IV, III, II y I, de los cuales el IV corresponde al Solutrense superior y el II al Solutrense superior evolucionado.

El tratamiento químico de las muestras ha sido doble. Las inferiores $(297-177 \mathrm{~cm}$.) se trataron de la forma que tradicionalmente hacemos en sedimentos arqueológicos: $\mathrm{ClH}$ en frío, $\mathrm{NaOH}$ al $20 \%$ en caliente, y posterior concentración en líquido denso, Thoulet, con una densidad de 2. Como los resultados obtenidos no eran muy satisfactorios, optamos por cambiar de sistema, teniendo en cuenta el tipo de sedimento con el que nos encontrábamos.

El nuevo proceso es el propuesto por A. I. Woosley (1978) para la extracción de pólen en sedimentos áridos, denominado, método Chevron. 


\section{Resultados:}

La frecuencia polínica es muy baja, ya que ha habido que leer seis láminas por muestra para obtener un número de palinomorfos suficientes para poder realizar los porcentajes con una cierta fiabilidad. Tenemos que señalar que a partir de la muestra en la que aplicamos el método Chevron, hemos encontrado elementos nuevos. Se trata de microorganismos pertenecientes al grupo de Dinoflagellata. Los de cueva Ambrosio pertenecen a los denominados Spiniferites ramosus (Ehrenberg) Sarjeant, de estratigrafía cuartenaria y a Cleistosphaeridium ancoriferum (Cookson and Eisenack) Davey, Downie Sarjeant Williams, del Cretácico superior (Caratini, comunicación escrita). Aunque presentes en todas las muestras, su porcentaje aumenta en aquellas estériles arqueológicamente, y casi estériles polínicamente. Su presencia puede explicarse en el hecho de tratarse de un sedimento procedente de arcillas de descalcificación del Cretácico.

Las muestras que ofrecieron datos válidos palinológicamente son las correspondientes a los niveles IV y VIla de la columna norte, y VI y VIIa de la sur. En todas las de la primera domina el Pinus silvestris. Junto a éste aparece Quercus t. ilex-coccifera, oleáceas y Ulmus. A partir de los 97 $\mathrm{cm}$. aumenta el Quercus, apareciendo Corylus, disminuyendo considerablemente los valores de los pinos. Entre las herbáceas destaca la presencia de Asteráceas ligulifloras, seguidas de las Poáceas, Fabáceas y Borragináceas. Nos encontramos en una fase templada, poco húmeda. Entre los 47 y los $27 \mathrm{~cm}$. descienden los valores de Pinus t. silvestris, aumentando los de Quercus t. ilex-coccifera y Corylus, apareciendo por vez primera los tilos (Tilia) que llegan a alcanzar valores de 6\%. Desaparecen las Asteráceas, aumentando las Poáceas, Borragináceas, Labiadas y Cyperáceas. Los Dinoflagelados han desaparecido. Se trata de una fase más templada y húmeda.

La columna sur presenta, al igual que la norte, una alternancia de niveles estériles con otros que, aunque no son ricos, sí son válidos para poder establecer porcentajes.

Se trata de la parte superior del nivel VIIa y el VI, que por estar acuñado no aparece en la columna anterior, si bien puede considerarse continuación de aquél. Palinológicamente no supone una ruptura. Habíamos visto que en el nivel VIIa disminuían los pinos, aumentando las encinas y los avellanos, hecho que se ve bien reflejado ahora. El resto de los árboles son similares, pudiéndose contabilizar algunos pólenes de Buxus. Entre las herbáceas dominan Asteráceas y Quenopodiáceas, habiendo algún pólen de Ephedra. Se trata de un momento seco. El nivel V presenta como árbol dominante el pino, seguido del olmo. Entre las herbáceas destacan Asteráceas, Poáceas, Cyperáceas, Nympháceas, Iridáceas y Juncáceas.

Extrapolando ambas columnas, y situando los niveles correlativamente, podemos situar el nivel VIIa en el interestadial Laugerie, fase templada, poco húmeda, con alto porcentaje arbóreo (75\%). Este disminuye a la mitad en el nivel VI. El nivel IV presenta una nueva subida arbórea, alcanzando el 70\%, con esencias termófilas y húmedas como son el avellano y el tilo. Podría situarse en el interestadio Lascaux.

\section{Cueva del Calor}

Se sitúa en la Sierra de Peña Rubia, en el límite entre las cuencas de los ríos Argos y Quipar, formada por materiales del Jurásico y Cretácico inferior en perfecta continuidad. Dentro de este contexto estructural y estratigráfico, la Cueva del Calor se desarrolla a favor de una de las fracturas perpendicular al contacto mecánico principal que limita la Sierra en su borde oriental. La cueva se halla encajada en unos potentes estratos de calizas micríticas de gran pureza del Jurásico medio en las que no se advierten superficies de estratificación. 
Clima y vegetacion actuales:

El ecoclima actual está en el límite de las posibilidades de albergar un bosque mediterráneo esclerófilo. Está presente el Quercus t. coccifera y Pinus halepensis. Pistacia lentiscus indica la filiación termófila del encinar. Junto a éste está presente Crataegus monogyma, Rosa arvensis, Prunus spinosa, Paeonia teroi, Acer granatenses y Quercus faginea. En una zona próxima a Peña Rubia hay algunos grupos de Buxus sempervivens, Aretostaphilos uvaursi y otras formaciones de robledales subhúmedos (Montiel s.a.).

\section{Estratigrafia arqueológica:}

Nivel V: Corresponde al primer momento de la ocupación de la cueva, en el que ésta se utiliza como hábitat, aunque no puede descartarse aún la presencia de enterramientos. Se trata de un solo momento cultural sin que pueda hablarse de secuencia evolutiva. Puede incluirse en el Neolítico medio-final.

Nivel IV: Se trata de un nivel en el que la cueva se ocupa como lugar de enterramientos múltiples. El rito puede ser el de cremación parcial. Se clasifica en el Eneolítico.

Nivel III: Poco documentado. Se define su asignación, momento argárico, por la presencia de un fragmento de la forma 5 procedente del nivel removido de la cueva (nivel I) y de dos pequeñas tulipas completas halladas in situ.

Nivel II: Iberromano: La cueva debió usarse como santuario.

Nivel I: Removido. (M. San Nicolás: comunicación personal.)

\section{Muestreo:}

Las muestras para el análisis polínico corresponden a dos series independientes por su desplazamiento lateral $(1 \mathrm{~m}$.), pero con una sucesión estratigráfica que abarca toda la secuencia inalterada. Se ha tomado en el único lugar donde esto es posible, ya que el resto de la cueva presenta el relleno removido o está sin excavar.

El lugar corresponde a los perfiles suroeste de los cuadros 180, para la primera serie (425-100 $\mathrm{cm}$.), y 170 para la segunda, superando la cota 0 , dando valores positivos. La toma de muestras se inició en los estratos prehistóricos, desechándose el I, siendo éste el resultado de una sucesiva remoción del relleno por parte de clandestinos. Igualmente se abandonó el II, correspondiente a un santuario fechado en época romana, situándose entre finales del siglo I y II-II de la Era.

La primera serie corresponde a todo el nivel III, fechado como argárico. La segunda corresponde a los niveles IV, V, VI, fechados en un momento del Neolítico final-Calcolítico.

Se han tratado un total de 26 muestras tomadas cada $5 \mathrm{~cm}$., en unos casos y cada $10 \mathrm{~cm}$., en otros. El tratamiento utilizado ha sido el normalmente aplicado por nosotros, y que ya hemos expuesto anteriormente. Se han leído cuatro láminas por muestra, obteniéndose resultados muy variados que oscilan entre 4 y 1.910 palinoformos. En general, el pólen está bien conservado y el número de taxones encontrados ha sido sufiente (60).

\section{Resultados:}

En el diagrama pueden verse tres fases: a) Situada entre los -240 y $-190 \mathrm{~cm}$., correspondiendo a los niveles inferiores del yacimiento. En ella puede verse que el porcentaje arbóreo no alcanza nunca el 50\%. Es notoria la presencia de especies mediterráneas junto a Quercus t. ilex, seguidas por Pinus halepensis, Ulmus, Populus, y en menor grado Juglans. Nos encontramos ante un bosque abierto de tipo mediterráneo. Entre las herbáceas dominan la Asteráceas ligulifloras, alcanzando en esta primera etapa valores hasta de un 30\%. Están seguidas en sus valores por las Poáceas, siendo interesante señalar que es en este momento donde mayor número de pólenes de cereal hemos localizado. Es importante también el porcentaje de plantas amantes de humedad como pueden ser las Cyperáceas, Juncáceas o Nympháceas. Los helechos no son muy significativos en este momento, 
aunque su presencia queda constatada. Es importante apuntar la presencia de Ranunculáceas, Polygonáceas, Cruciferas o Fabáceas, indicando que los cultivos tenian una cierta importancia en estos momentos. Es ahora también cuando mayor importancia tiene el porcentaje de Vitis (9\%). Es posible, pues, que nos encontremos en un momento de fuerte acción antrópica dentro de un clima templado y no excesivamente seco. b) La etapa siguiente podemos enmarcarla entre los -180 y $-90 \mathrm{~cm}$., teniendo en cuenta que, como hemos señalado anteriormente, el intervalo entre los $150 \mathrm{y}$ $100 \mathrm{~cm}$., no es observable a nivel sedimentológico, sino que es continuación entre uno y otro cortes. Aquí los pinos superan ligeramente los valores de las encinas y las especies mediterráneas. Siguen en los mismos valores los olmos, disminuyendo los álamos (Populus) y los nogales (Juglans), haciendo una tímida aparición los tilos (Tilia). Entre las herbáceas, disminuyen las Poáceas, teniendo una importante subida las Asteráceas ligulifloras que de alguna manera cubren los valores que antes tenian otras herbáceas. Están presentes asimismo las Carduáceas y Artemisia. Disminuye el porcentaje de cereales, así como el de las plantas ruderales, cortejo de los anteriores en los campos cultivados. Han disminuido igualmente las "plantas húmedas". c) Tras el lapsus producido entre $-80 \mathrm{y}-45 \mathrm{~cm}$., por la pobreza del número de palinoformos, encontramos la parte superior, entre -45 y $-25 \mathrm{~cm}$., donde el porcentaje arbóreo sube considerablemente debido al aumento de Pinus halepensis. Es difícil considerar si este aumento se debe a la presencia de un mayor masa boscosa o al alto grado de polinización y desplazamiento de los pólenes de esta familia. Las especies mediterráneas siguen presentes, así como los valores de Quercus ilex. El resto de los árboles están representados por valores muy bajos. Entre las herbáceas siguen predominando las Asteráceas ligulifloras, aumentando la presencia de Ephedra. Las Poáceas están prácticamente ausentes. En definitiva, podemos señalar que la vegetación está formada por el Quercetum mixtum, dada la presencia de elementos característicos de éste, como son los olmos y los tilos, y de taxones termófilos presentes en la actualidad.

\section{Abrigo del Milano}

Se sitúa en un escarpe localizado en un afloramiento subbético de calizas del Eoceno medio. Se trata de una pequeña concavidad de la roca de planta semicircular, cuya pared aumenta en altura hacia el centro, en la que se encuentra el sepulcro.

\section{Vegetación actual:}

La mayor parte de la comarca del Noroeste murciano se encuentra encuadrada en cinco dominios climáticos, muy mermados por la acción del hombre. La localidad de Mula, a la que pertenece el yacimiento se encuadra en el dominio de Quercion Rotundifoliae. En éste son frecuentes las comunidades de matorrales y tomillares. Dentro de este dominio se distinguen dos alianzas: la Quercion Rotundifoliae y la Rosmarino-Ericion (González Ortiz, 1984). Las pocas reliquias que quedan están reducidas a especies arbustivas, siendo frecuente la mezcla de encinas con Pinus halepensis, especialmente en las zonas más térmicas. Se encuentra aislado el Juniperus thurifera y el oxicedrus. El matorral de romero y brezo está muy extendido en la comarca, estando formado por arbustos y plantas leñosas, habiendo algunos ejemplares de pinos carrascos dispersos entre ellos. Son frecuentes las formaciones de Stipa tenacissima.

\section{Muestreo y tratamiento:}

La muestra está recogida en el interior de la zona más antigua del sepulcro, estando en contacto con los enterramientos, fechados en el 5320 B.P. El estudio sedimentológico ha señalado que el sedimento es de origen antrópico, resultando del relleno de la cámara sepulcral. El tratamiento 
quimico ha sido el habitual, y el número de palinoformos ha sido de 764 , resultado de la lectura de cuatro láminas.

\section{Resultados:}

Entre el pólen arbóreo destaca la presencia de pino carrasco con un 20\%, habiendo escasos ejemplares de fresnos (Fraxinus) y de encinas (Qercus $t$. ilex). Entre las herbáceas destacan las plantas próximas a los cursos de agua, como son el caso de las Alismatáceas, Juncáceas o los distintos tipos de esporas que se han localizado. Parece que en el momento de producirse el enterramiento el medio estaba bastante deforestado, puesto que a excepción de los pinos el medio arbóreo era escasísimo. La no existencia de pólenes de cereales o de plantas ruderales parece indicar que en la zona próxima no existian campos de cultivo.

\section{Yacimiento de Almizaraque}

Se trata de un cabezo o tell de $100 \mathrm{~m}$. de largo por 50 de ancho, situado sobre aluviones cuaternarios pertenecientes a la última terraza del río Almanzora, de matriz arcillosa.

\section{Vegetación actual:}

El sudeste ibérico comprende algunos de los territorios de aridez más acusada de la Península. Pese a esta aridez generalizada hay suficientes variaciones litológicas, edáficas y bioclimáticas como para permitir la existencia de distintos ecosistemas, agrupados en 11 series, que se engloban en tres grandes conjuntos: series de lentiscares y espinales termomediterráneos; series de coscojares termo y mesomediterráneos y series de carrascales termo-mesomediterráneos (Alcaraz y Peinado, 1987). La vegetación del área donde se sitúa el yacimiento de Almizaraque corresponde a una de las series no determinadas por el clima general, sino por factores que se superponen al climático, como son los edáficos, halófilos, etc. Así podemos hablar de la geoserie de ramblas con adelfas (Nerium oleander), constituyendo la asociación Rubio longifoliae, Nerietum oleandri. Cuando los suelos son algo limosos, entran comunidades dominadas por tarays (Tamarix canariensis) pertenecientes a la asociación Glycirrhizo glabrae-Tamaricetum canariensis. Donde el agua se acumula durante cierto tiempo llegan a instalarse fragmentos de series ripicolas, con cañas, Arundo donax, álamos, olmos y juncos Juncos litoralis, etc. En las depresiones margosas y esquistosas es frecuente la entrada del freatófito Ziziphus lotus. En estas depresiones hay que considerar a las comunidades de este arbusto espinoso como la vegetación terminal.

\section{Estratigrafía arqueológica:}

Se observan dos o tres niveles de habitación superpuestos:

Fase I, formada por un relleno de una potencia de $50 \mathrm{~cm}$., con débiles construcciones, silos excavados y hoyos de postes.

Fase II, frecuente en construcciones. El final de esta fase está fechado en el $2170 \pm 100$ a.C.

Fase III, formada por acumulación de tierras limosas compactas de textura uniforme, con bolsadas de cenizas, restos de adobes. La parte superior de ésta está fechada en el $2000 \pm 100$ a.C.

Fase IV. Presenta una gran actividad constructiva con restos de zócalos de cabañas.

Fase V, conservada desigualmente, está afectada por construcciones posteriores y por la erosión de la ladera.

Culturalmente el yacimiento se enmarca en el Calcolítico del SE, con materiales propios de este período y con una actividad económica centrada en la agricultura y ganadería (Delibes et al., 1986). 
Muestreo y resultados:

El estudio polínico se efectuó sobre un total de 15 muestras recogidas cada $10 \mathrm{~cm}$., pudiéndose observar dos partes:

- la inferior (90-180 cm.) queda marcada por el dominio de Pinus halepensis, acompañado por taxones mediterráneos, como Buxus sempervivens o Vitis vinifera, quedando atestiguados cultivos agrícolas, Cerealia, junto a Fabáceas Plantago y Polygonáceas.

- la superior, en la que los pinos disminuyen, y los espacios abiertos se ven ocupados por Asteráceas ligulifloras y Quenopodiáceas. Parece corresponder con la fase de abandono del yacimiento, con una vegetación próxima a la de la actualidad del tipo xerófilo propia de un clima extremadamente seco. La presencia de Hystrichosferos concentricistes puede deberse al hecho de que en la base del tell se acumulara agua en determinados momentos.

\section{Yacimiento de El Prado}

Se encuentra situado en la localidad de Jumilla (Murcia). Se trata de una cubeta endorreica rellenada por glacis de acumulación con tres grupos de estratos cuya formación está relacionada con los cambios climáticos del Cuaternario. El yacimiento se sitúa en la denominada Rambla del Judío, donde su cauce desaparece bajo la acción del hombre.

\section{Clima y vegetación actuales:}

Las condiciones climáticas de la zona son resultado de la dinámica atmosférica general de la zona levantina, modificadas por una serie de factores como son la altitud y la continentalidad. Tiene una pluviosidad media anual entre 292 y $333 \mathrm{~mm}$., quedando en el límite entre la España seca y la subdesértica.

La vegetación actual está formada por la alianza Quercion rotundifoliae con Quercus t. ilex rotundifolia y Pinus halepensis. En altitudes superiores a $1.000 \mathrm{~m}$., se les une Pinus laricio junto a matorral de alta montaña: Bella spinosa, Bupteurum rigidum, Quercus coccifera, Pistacia lentiscus, Rosmarinus officinalis, Rhamnus lycoides, Lavandula latifolia, Arbustus unedo, y Cistus albidus (Morales, 1972).

\section{Estratigrafía arqueológica:}

El depósito arqueológico tiene una potencia de 2,5 m., situándose bajo una potente capa de arcilla estéril. Presenta cinco niveles arqueológicos. La humedad del nivel 5 parece haberse debido al ascenso del nivel freático con inundación de la capa impermeable de arcilla. El 4 sugiere condiciones más secas. Como el 3, contiene áreas con cenizas, siendo los más ricos en materiales. El 4 está fechado en el $3950 \pm 160$ B.P. y $4170 \pm 50$ B.P. y el 5, entre $4350 \pm 50$ B.P. y el $4180 \pm 50$ B.P. Los materiales, muy uniformes en los tres últimos niveles se incluyen en el Calcolítico del SE peninsular (Walker, 1985).

\section{Muestreo y tratamiento:}

Se han analizado un total de 20 muestras correspondientes a los niveles 2 a $5 \mathrm{~d}$ de la cuadrícula $Z$ I del perfil sur, con una profundidad entre 40 y $240 \mathrm{~cm}$. Los resultados entre una y otras, respecto al número de palinomorfos, han sido muy desiguales, siendo muy escaso el número de taxones, incluso en aquellas en las que el número de palinomorfos ha sido mayor. Por esta razón los resultados a los que hemos llegado son, de momento, parciales. El tratamiento químico ha sido el clásico, sin que haya que haber utilizado ningún procedimiento complementario. 


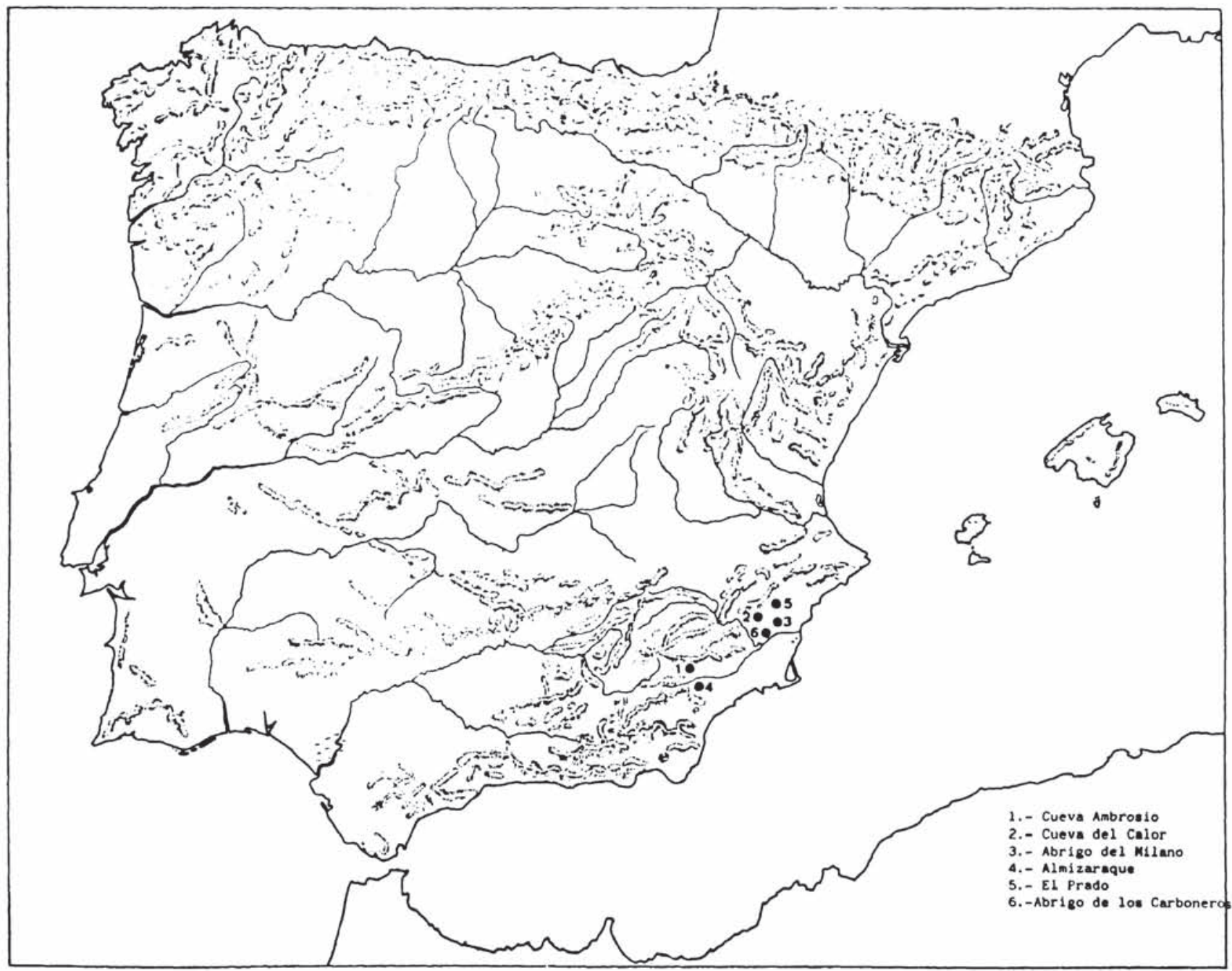

FIG. 1.- Localización de los yacimientos mencionados en el texto.

\section{Resultados:}

No hemos realizado un diagrama clásico debido a que el número de muestras en las que se ha podido obtener un porcentaje válido es desigual. Dentro de lo poco que de momento podemos decir sobre las variaciones florísticas, señalaremos que, en líneas generales, destaca la presencia de Pinus halepensis, seguido por taxones mediterráneos entre los que hay que destacar las Oleáceas, Pistacia lentiscus, Buxus sempervivens y Cupresáceas. En alguna de las muestras se han localizado pólenes de olmos y álamos, sin que con ello podamos dar ninguna consideración especial. Entre las herbáceas, dominan las Quenopodiáceas y las Asteráceas ligulifloras, pudiendo indicar condiciones áridas. Esto mismo puede deducirse de la presencia de las Liliáceas, Malváceas o los escasos pólenes de Ephedra fragilis. Entre los 40 y los $130 \mathrm{~cm}$., aparecen algunos pólenes de Vitis vinifera, habiendo sido registrada su presencia entre los macrorrestos recuperados. Restos de otros cultivos pueden deducirse por la presencia de pólenes de cereal, aunque su porcentaje es muy bajo $(0,2 \%)$.

La pobreza en palinomorfos puede ser atribuida al tipo de sedimento, procedente en parte de arroyadas y con un alto contenido en yeso. La presencia de quistes de Hystrichosferos y algunas esporas monoletes nos lleva a pensar que en algunos momentos el yacimiento estuvo encharcado. 


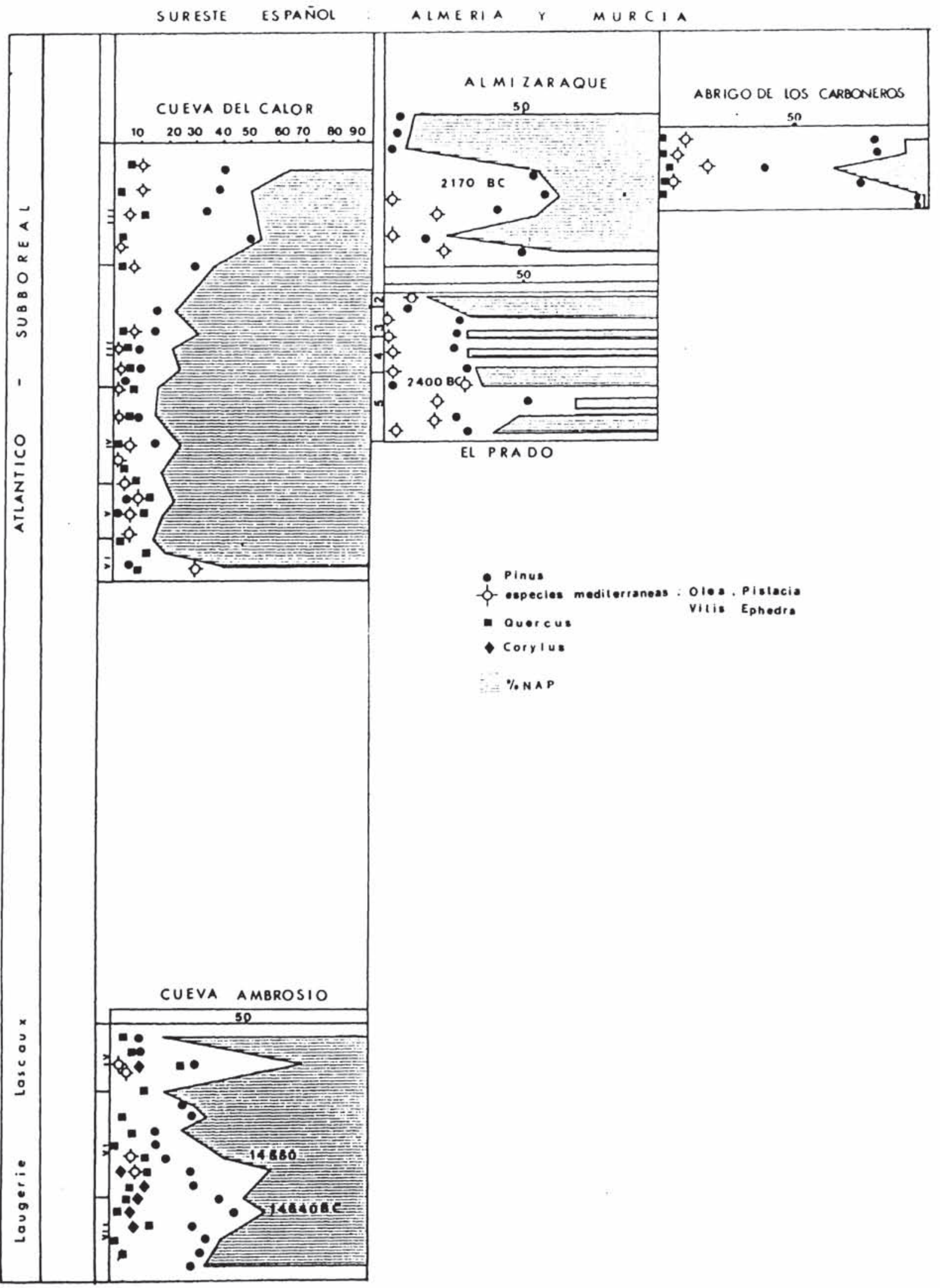

FIG. 2.-Diagramas simplificados de los yacimientos mencionados en el texto. 
Finalmente tenemos los resultados procedentes de otro yacimiento murciano cuya cronología parece situarse en un momento del Calcolitico, aunque se desconoce de momento su datación absoluta.

\section{Abrigo de los Carboneros}

Se sitúa en la localidad de Totana. Se trata de un abrigo sepulcral con las paredes recubiertas de yeso. El yacimiento corresponde a un enterramiento individual femenino.

\section{Vegetación actual:}

El valle del Guadalentín, donde se encuentra la vega de Totana corresponde a una zona eminentemente agrícola, ocupada por cultivos de diversa índole, por lo que ofrece poco interés en cuanto a la vegetación espontánea. Los restos de unidades fitoclimáticas resultan reducidos y espaciados. El mayor dominio corresponde a las comunidades nitrófilas del orden Salsolo-Peganetalia de facies estepoide. El tomillar serial y formaciones de Salsolas y Artemisias cubren las áreas no cultivadas. La cota de máxima altitud es la Sierra de Espuña, cumbre llamada Morrón de Totana. En dicha sierra se acumula la masa vegetal más densa. En sus niveles más altos se conservan las unidades climax del orden Quercetalia ilicis, con Quercus rotundifoliae y Quercion eu-ilicis. Los cantiles superiores conservan una vegetación rupestre con afinidades béticas, mientras que en sus niveles inferiores las áreas deforestadas muestran comunidades de los órdenes Rosmarinetalia y Anthyllidetalia terniflorae con matorral serial, sufrutices de Cistáceas y Labiadas y céspedes de Aphyllation (Esteve, 1972).

\section{Datos arqueológicos:}

El hecho de que el yacimiento esté en período de estudio hace que no dispongamos de toda la información. Adelantaremos que se trata de un enterramiento femenino, descubierto por un grupo de clandestinos, lo que no ha permitido la localización del ajuar completo. El cadáver presentaba la cabeza vendada, correspondiendo la venda a Cannabis sindicus. El cuerpo estaba colocado sobre unos tablones de madera de nogal, cubierto todo ello por una estera de cáñamo.

\section{Muestreo:}

La columna polínica se tomó en el perfil longitudinal que corta estratigráficamente el sepulcro por la mitad. El nivel I está limitado por las cotas $-40,-85 \mathrm{~cm}$., comprendiendo los estratos Ib y Ic, siendo resultado de la acumulación del sedimiento posterior al enterramiento. El nivel II corresponde a la inhumación, y en él se han tomado una serie de seis muestras.

El tratamiento químico no ha presentado ningún problema por lo que se ha utilizado el sistema tradicional.

\section{Resultados:}

El porcentaje arbóreo supera con mucho al de herbáceas, debido al alto porcentaje de Pinus halepensis, acompañados por algunos taxones típicamente mediterráneos como son Quercus ilex, Pistacia, Olea, Ephedra o Vitis, aunque su porcentaje es bajo. La diferencia entre el nivel inferior a la deposición del cadáver y el posterior a ésta es poco visible, a no ser por los porcentajes de algunas plantas, como el caso de Ephedra o Artemisia, pasando en el primer caso de un 14,6\% en la 
muestra inmediatamente superior al cadáver a un 2,1\% en la inmediatamente inferior. En el caso de Artemisia pasa de un $9,4 \%$ a un $4,8 \%$. Estos datos nos llevan a suponer que se debió depositar algún ramillete de flores, hecho constatado en otras sepulturas pertenecientes a diversos períodos culturales (Leroi-Gourhan, 1968; Bui-Thi-Mai, Girard y Renault-Miskovsky, 1983; Girard, 1986).

La composición florística de éste puede indicar que el enterramiento se efectuó en primavera.

La presencia de algún pólen de cereal y de Plantago indica la existencia de cultivos en zonas próximas al lugar del enterramiento.

\section{CONCLUSIONES}

Hemos revisado seis yacimientos de una región homogénea desde el punto de vista climático y de vegetación. No vamos a hablar de conclusiones de carácter general puesto que los datos son todavía insuficientes, pero sí es una primera aproximación a una región en la que no se tenía ningún tipo de referencia paleoclimática.

Es interesante señalar que los cambios ocurridos en la vegetación no han sido significativos, apareciendo los taxones, considerados típicos, de carácter estrictamente mediterráneo, y que están presentes en la actualidad. Tanto en la cueva de Ambrosio como en la del Calor, los resultados parecen indicar que el valor de las precipitaciones podía ser superior a lo que es en la actualidad. El resto de los yacimientos muestran que la antropización de las áreas donde se localizan era muy fuerte en el momento de su existencia, por lo que la vegetación muestra las alteraciones propias de la acción del hombre. Esta alteración se ve particularmente incrementada en los dos abrigos dedicados a sepulcros como son el del Milano y el de los Carboneros.

\section{BIBLIOGRAFIA}

Alcaraz, F. y Peinado, M. (1987): «España semiárida: Murcia y Almeria». En: La vegetación de España. Colección Aula Abierta. pp. 257-280.

BUI-ThI-MAI; GIRARD, M., y Renault-MiskovSKY, J. (1983): "L'analyse pollinique dans les sepultures et Analyses polliniques du Sarcophage 18 de l'Abbaye Saint-Victor (Marseille)". Notes internes 46 du Centre de Recherches Archéologiques. 15 pp.

Delibes, G.; Fernández Miranda, M.; Fernández-Posse, M. D., y Martín Morales, C. (1986): «El poblado de Almizaraquen. Homenaje a Luis Siret (1934-1984). Consejería de Cultura de la Junta de Andalucía. pp. 167-177.

Esteve Chueca, F. (1972): Vegetación y flora de las regiones central y meridional de la provincia de Murcia. C.E.B.A.S. 451 pp.

GIRARD, M. (1986): "Les restes végétaux discrets dans les sépultures. Recherche et enseignements». Archéologie Médiévale, XVI. pp. 138-145.

GonzÁlez ORTIZ, J. L. (1984): El Noroeste Murciano. El hombre y sus tierras. Ediciones Mediterráneo.

Lerol-Gourhan, Arl. (1968): «Le Néanderthalien IV de Shanidan. Bull. Soc. Préhist. Française. C.R.S.M. n. ${ }^{2}$, pp. 79-83.

MonTIEL VILA, J. (inédito): Primera aproximación a la reconstrucción paleoclimatica de la cueva del Calor. Texto mecanografiado.

MoRALES, A. (1972): El altiplano de Jumilla-Yecla.Departamento de Geografia. Universidad de Murcia. 467 pp.

RIPOLl LóPEZ, S. (1986): «El Solutrense de Cueva Ambrosio. Vélez-Blanco, Almería, campaña de 1963. Excavaciones Arqueológicas en España, 148. 205 pp.

- (1987): La Cueva de Ambrosio: su posición cronoestratigráfica en el Mediterráneo occidental. Tesis doctoral, inédita, leída en la UNED el 1 de julio de 1987.

WALKER, W. (1985): «El Prado and the Southeaster Spanish Chalcolitic». Research Report of the National Society, 20. pp. 799-834.

WoosLeY, A. (1978): «Pollen extraction for Arid-land sediments». Journal of Field Archaeology, 5(3), pp. $349-355$. 